IN THE RED CROSS WORLD

\title{
THE HENRY DUNANT INSTITUTE
}

\section{Research}

For a century Red Cross activities have ceaselessly diversified and multiplied. However, the effectiveness of an action depends to a very great extent on the sum of thought and study which has preceded it. Hence the fundamental and often misunderstood importance of the immense research work which the Red Cross has to undertake in so many fields: sociology, law, the study of conflicts, the study of natural disasters, social medicine, military medicine, pedagogy, etc...

As the "instrument for study and research" its founders intended it to be, the Henry Dunant Institute is faced in this connection with specific responsibilities.

As has already been explained in a previous article ${ }^{1}$, the Institute has undertaken to draw up as complete an inventory as possible of research needs for the International Committee, the League and National Societies. This work can only be carried out through close contacts among all agencies of the Red Cross and the first circular will soon be sent to National Societies requesting them to state in what fields research would be useful for them.

The Institute will not limit itself to this work of recording subjects for scientific research. It will especially endeavour to promote research on specific points brought to its attention. It will disseminate these themes for research in universities and specialised institutes throughout the whole world, in order to interest aspirants for doctor degrees or other university honours, as well as research workers.

After finding a person competent to deal with a particular subject suggested by it, the Institute will follow his work closely. It will remain available to that person throughout the research

1 International Review of the Red Cross, April 1969. 
work. In this field of documentation, the Institute has already assisted several research workers. It has also contributed to the general guidance of their efforts. In some cases, where it appeared justified, it also gave material assistance.

In a somewhat more distant future, when the Institute will have been able to build up its services, it will itself undertake to reply to requests for research by Red Cross agencies. Already its staff are preparing several publications and for that purpose are carrying out historical, legal and sociological studies. In addition, they are intensifying their contacts with other institutes in Geneva and elsewhere, thereby preparing the ground for fruitful co-operation. 